\title{
Contribuição ao conhecimento de Byttneria seção Vahihara (Malvaceae) para o estado do Pará, Brasil
}

\author{
Contribution to the knowledge of Byttneria section Vahihara (Malvaceae) \\ from Pará state, Brazil
}

Rayssa Costa da Silva Ribeiro ${ }^{1}$, Aluisio José Fernandes-Júnior ${ }^{2,3}$, Ana Kelly Koch ${ }^{2}$ \& Anna Luiza Ilkiu-Borges ${ }^{1}$

\begin{abstract}
Resumo
Byttneria catalpifolia subsp. catalpifolia é apresentada como um novo registro e Byttneria fulva como uma redescoberta para o estado do Pará, ambas com base em coleções provenientes da região da Volta Grande do rio Xingu. Descrições morfológicas, dados de distribuição geográfica e ilustrações das espécies são fornecidos, e são discutidas as afinidades taxonômicas das duas espécies.
\end{abstract}

Palavras-chave: Amazônia, distribuição, taxonomia, Xingu.

\begin{abstract}
Byttneria catalpifolia subsp. catalpifolia is presented as a new record and the rediscovery of Byttneria fulva for the Pará state, based on collections from the region of the Volta Grande of Xingu river. Morphological descriptions, geographic distribution data and illustrations are presente, and taxonomic relationships of the two species are discussed.
\end{abstract}

Key words: Amazon, distribution, taxonomy, Xingu.

Byttneria Loefl. é um gênero pantropical que pertence à Byttnerioideae, uma das nove subfamílias de Malvaceae (Bayer et al. 1999; Bayer \& Kubitzki 2003) com 138 espécies distribuídas nas regiões tropicais e subtropicais, predominantemente na América do Sul (Cristóbal 1976; Cristóbal 2007). No Brasil, o gênero está representado por 52 espécies, das quais 11 ocorrem no Pará (Cristóbal 1976).

O gênero é caracterizado por apresentar pétalas unguiculadas, geralmente carnosas com a base adnata ao tubo estaminal, formado por cinco estames e cinco estaminódios, assim como por apresentarem nectários na face abaxial das lâminas foliares e cápsula com proeminências na face dorsal (Cristóbal 1976). Byttneria está classificado em seis seções (Cristóbal 1976). As espécies tratadas no presente estudo pertencem a seção Vahihara J.Ar., que é caracterizada pelo hábito lianescente e conectivo inconspícuo ( $v S$. conectivo articulado ao filete).
No Pará, uma das áreas que necessitam de maior atenção quanto ao conhecimento de sua flora é a região da Volta Grande do rio Xingu, a qual vem passando por consideráveis mudanças na sua cobertura vegetal original devido principalmente à forte ação antrópica presente na zona de influência da rodovia Transamazônica (BR-230) e com a construção da Usina Hidrelétrica de Belo Monte (Salomão et al. 2007; Carneiro-Silva et al. 2015; Koch et al. 2015; Pantoja et al. 2015).

Durante o levantamento da flora de Malvales da região da Volta Grande do rio Xingu, duas espécies de Byttneria foram identificadas como novidades para a flora no estado Pará, com base no material proveniente do Projeto Salvamento e Aproveitamento Científico da Flora da UHE Belo Monte. Deste modo, o presente trabalho tem como objetivo contribuir para o conhecimento sobre a distribuição geográfica de $B$. catalpifolia subsp. catalpifolia e $B$. fulva, além de fornecer comentários taxonômicos e ilustrações dessas espécies.

\footnotetext{
${ }^{1}$ Museu Paraense Emílio Goeldi, Coord. Botânica, Av. Perimetral 1901, Terra Firme, 66077-830, Belém, PA, Brasil.

${ }^{2}$ Museu Paraense Emílio Goeldi, Coord. Botânica, Prog. Capacitação Institucional, Av. Perimetral 1901, Terra Firme, 66077-830, Belém, PA, Brasil.

${ }^{3}$ Autor para correspondência: ajfernandesjunior@gmail.com
} 


\section{Taxonomia}

1. Byttneria catalpifolia Jacq. subsp. catalpifolia, Pl. Hort. Schoenbr. 1: 21-22. 1797.

Figs.1 a-c; 2

Lianas, ramos cilíndricos, pubescentes, com tricomas estrelados e glandulares avermelhados ou esbranquiçados. Estípulas caducas. Folhas dísticas; pecíolos 2,3-4,1 cm compr., pubescentes, indumento igual ao dos ramos e mais densos na porção apical do pecíolo; lâminas foliares $8,1-10,5 \times 4,2-6 \mathrm{~cm}$, concolores, inteiras, palmatinérveas, 5-nervadas, ovadas, base arredondada, ápice acuminado, margem inteira, face adaxial glabrescente, com tricomas estrelados diminutos e esparsos, face abaxial pubescente com tricomas estrelados diminutos mais densos sobre as nervuras próximo a porção basal da lâmina; nectário localizado sobre a base da nervura principal. Inflorescências axilares ou terminais. Flores dispostas em cimeiras de 3-4 flores, pedicelo 1-3 mm compr., tomentoso, tricomas estrelados diminutos, cálice com 5 sépalas lanceoladas, 4-5 $\mathrm{mm}$ compr., profundamente lobado desde a base, externamente pubescente com tricomas estrelados diminutos, internamente pubescente na metade apical com tricomas estrelados e na metade basal com tricomas glandulares; pétalas $5-5,1 \mathrm{~mm}$ compr., brancas, unguiculadas, capuz não alado, inserido no tubo estaminal pela face anterior, lâminas lanceoladas, aplanadas e com margem inteira; tubo estaminal 1,35-1,6 mm compr., filetes subsésseis dispostos em 5 grupos adnatos ao tubo, anteras dorsifixas, deiscência longitudinal; ovário globoso, 5-locular, glabro, estigma capitado. Frutos e sementes não vistos.

Material examinado: Altamira, Rio Xingu, Transamazônica Km 46, Travessão 17, Largo do Passai, 4.II.1987, fl., A.T.G. Dias et al. 1147 (MG).

Byttneria catalpifolia é uma espécie composta por duas subespécies: B. catalpifolia subsp. catalpifolia que é encontrada nas Américas e caracterizada por apresentar tricomas estrelados nas lâminas foliares; e B. catalpifolia subsp. africana (Mast.) Exell \& Mendonça, que ocorre na África (Angola, Congo, Costa do Marfim, Gabão e Uganda) e apresenta tricomas simples nas lâminas foliares (Cristóbal 1976).

Byttneria catalpifolia subsp. catalpifolia apresenta a maior área de distribuição entre as espécies do gênero, ocorrendo no México, Guatemala, Honduras, El Salvador, Nicarágua, Costa Rica, República Dominicana, Trinidad e Tobago, Venezuela, Colômbia, Equador, Peru,
Bolívia e no Brasil (Bahia, Ceará, Espírito Santo, Goiás, Minas Gerais, Paraná, Pernambuco, Rio de Janeiro e São Paulo) (Cristóbal 1976). Nenhum trabalho apontou a ocorrência de B. catalpifolia subsp. catalpifolia para a região Norte, sendo esse o primeiro registro para o estado do Pará e para a região Amazônica no Brasil (Fig. 2).

A susbespécie catalpifolia caracteriza-se por apresentar pétalas planas (vs. cilíndricas ou claviformes nas demais espécies da seção Vahihara), além da ausência de fossa na região onde se insere no tubo estaminal (vs. presença de fossa nas pétalas), sendo esta mais plana, carnosa e com margem irregular (Cristóbal 1976). Segundo Cruz (2007), B. catalpifolia subsp. catalpifolia pode ser encontrada em áreas de cerrado e floresta estacional semidecidual na borda e no interior de mata. No Pará, foi encontrada em floresta de terra firma aberta.

2. Byttneria fulva Poepp. \& Endl., Nov. Gen. Sp. Pl. 3: 73. 1845 Figs. $1 \mathrm{~d}-\mathrm{e} ; 2$

Lianas, ramos cilíndricos, tomentosoferrugíneos, tricomas estrelados e glandulares diminutos, dispersos. Estípulas caducas. Folhas dísticas; pecíolos 0,75-2,1 cm compr., indumento e tricomas iguais aos dos ramos; lâminas foliares $5,7-11,3 \mathrm{~cm} \times 1,9-5,1 \mathrm{~cm}$, discolores, inteiras, palmatinérvias, 3-nervadas, elípticas, oblanceoladas e oblonga-lanceolada, raro obovadas, base arredondada ou levemente atenuada, ápice acuminado ou agudo, margem inteira, face adaxial glabra, face abaxial tomentosa, com tricomas estrelados diminutos, adpressos, brancos ou amarelados, densamente distribuídos sobre as nervuras principais e secundárias; nectário localizado sobre a base da nervura principal. Inflorescências axilares ou em pequenos ramos laterais. Flores dispostas em densos fascículos, numerosas, pedicelos 0,4-1 mm compr., indumento e tricomas iguais aos dos ramos; cálice com 5 sépalas ovadas, $0,25-0,3 \mathrm{~mm}$ compr., profundamente lobado desde a base, pubescenteferrugíneo, externamente com tricomas estrelados diminutos e internamente com poucos tricomas sobre a nervura média; pétalas ca. $3 \mathrm{~mm}$ compr., amarelas, unguiculadas, porção inferior da unha estreitada formando um capuz acentuadamente canaliculado e alado, adnato ao tubo estaminal, lâmina lanceolada, carnosa e com margem inteira; tubo estaminal ca. $2 \mathrm{~mm}$ compr., filetes subsésseis, dispostos em 5 grupos adnatos ao tubo, anteras dorsifixas, deiscência longitudinal; ovário globoso, 


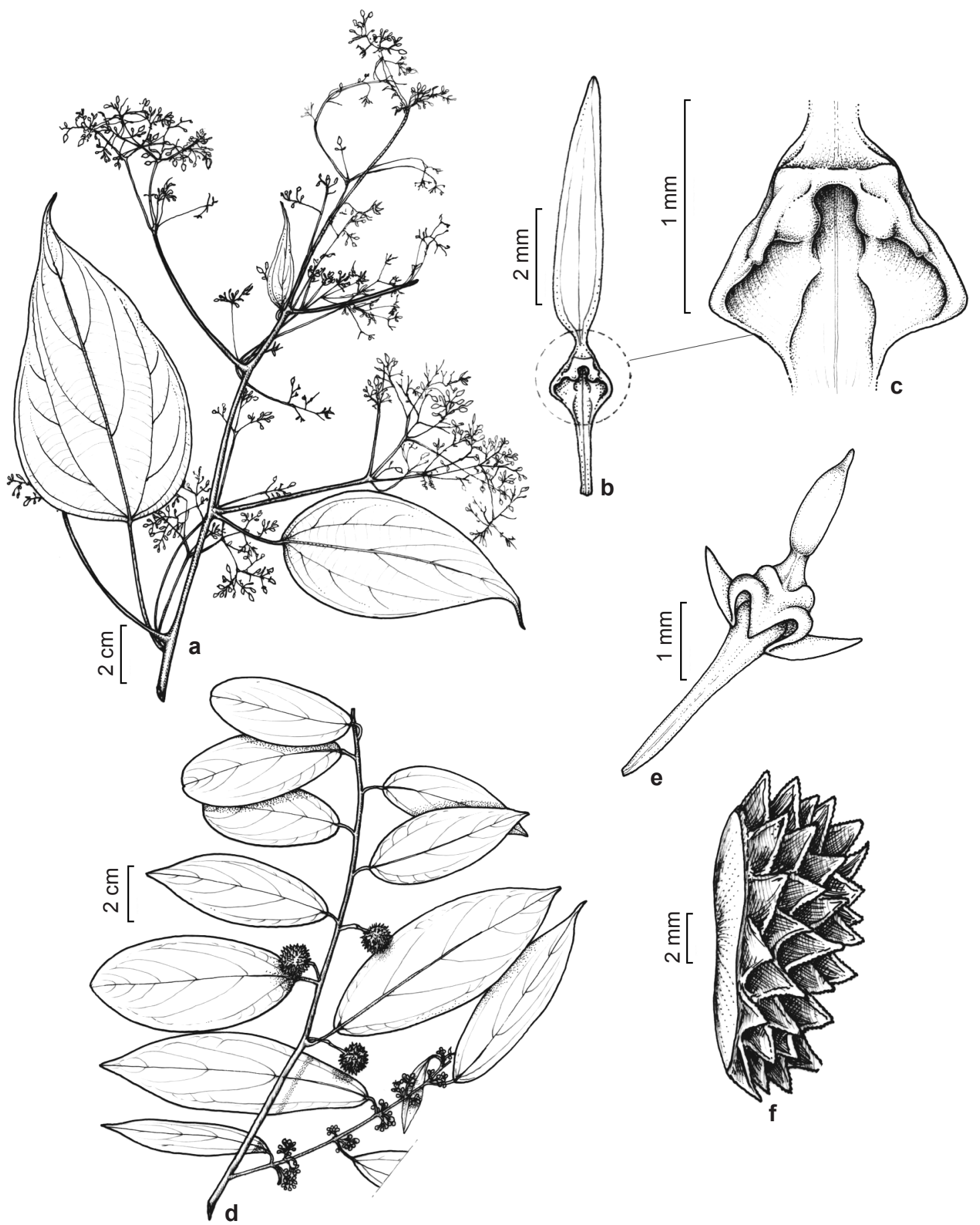

Figura 1 - Espécies de Byttneria seção Vahihara - a-c. Byttneria catalpifolia subsp. catalpifolia - a. ramo florido; b. pétala unguiculada, vista ventral; c. detalhe do capuz acentuadamente canaliculado e alado na pétala; d-f. Byttneria fulva - d. ramo com flores e frutos; e. pétala unguiculada, vista ventral; f. parte da cápsula, vista dorsal. Ilustrações: Carlos Alvarez (a-c. A.T.G. Dias et al. 1147; d-e. A.T.G. Dias 492; f. S.A.M. Souza et al. 1203).

Figure 1 - Species of the Byttneria section Vahihara - a-c. Byttneria catalpifolia subsp. catalpifolia - a. flowering branch; b. unguiculate petal, ventral view; c. detail of the hood remarkedly canaliculate and winged in the petal; d-f. Byttneria fulva-d. branch with flowers and fruits; e. unguiculate petal, ventral view; f. part of the capsule, dorsal view. Illustrations: Carlos Alvarez (a-c. A.T.G. Dias et al. 1147; d-e. A.T.G. Dias 492; f. S.A.M. Souza et al. 1203). 
5-locular, glabro; estilete ca. $2 \mathrm{~mm}$ compr. Fruto esquizocárpico, 1-1,2 $\mathrm{cm}$ diâmetro, globoso, deiscente, 5-mericarpos, $0,7-0,94 \times 0,4-0,5 \mathrm{~cm}$, mericarpos lenhosos com aculéolos agudos e rígidos com até $2,45 \mathrm{~mm}$ compr., tomentosos, com tricomas estrelados diminutos, ferruginosos e tricomas glandulares esbranquiçados, dispersos. Sementes 1 por mericarpo, $5 \mathrm{~mm}$ compr., ovadas, puberulentas, com tricomas estrelados amarelados. Material examinado: Altamira, margem direita do furo do Belo Sonho, 27.X.1986, fl., A.T.G. Dias 492 (MG); Ibid., margem direita do Rio Xingu, 12.X.1986, fl., R.T.P. et al. 245 (INPA, MG); lado esquerdo a jusante do Rio Xingu, no lago da ilha do Murici, 18.X.1986, fl., A.T.G. Dias 351 (MG); Rio Xingu, Ilha Grande no Bacabal, 14.II.1987, fr., S.A.M. Souza et al. 1203 (MG); Rio Xingu, Largo do Passai, 4.II.1987, fr., S.A.M. Souza et al. 1041 (MG); Óbidos, 18.XII. 1907, fl., A. Ducke 9168 (INPA, MG).

Byttneria fulva é encontrada na Colômbia, Peru e no Brasil (Acre, Amazonas, Mato Grosso e Rondônia) (Cristóbal 1976). Existe um único registro dessa espécie no Pará, um espécime coletado por Spruce em 1849, entre os municípios de Óbidos e Santarém (Spruce 404 em BM!, K!,

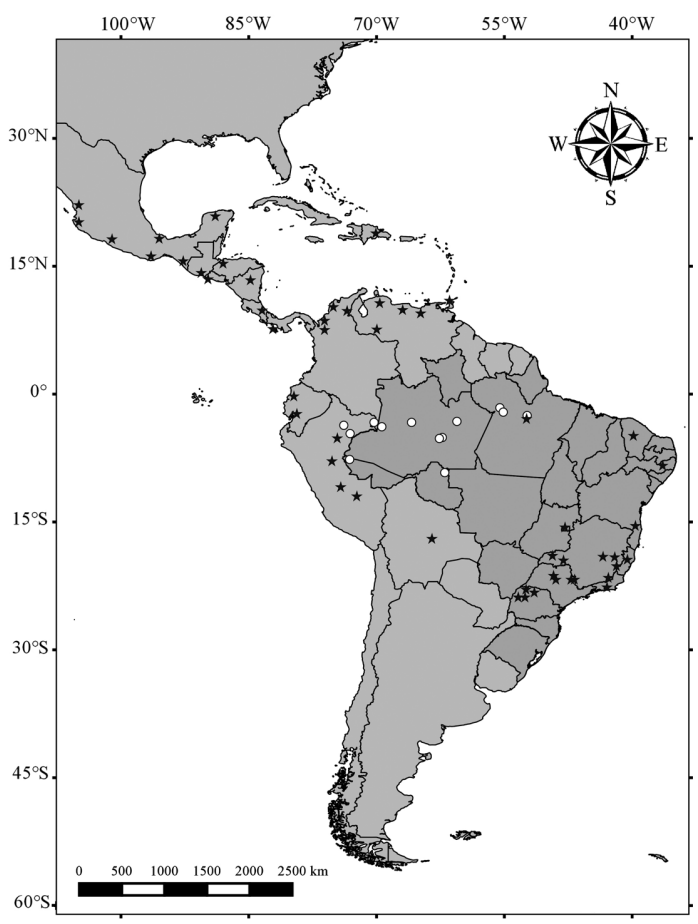

Figura 2 - Mapa de distribuição geográfica de Byttneria catalpifolia subsp. catalpifolia $(\star)$ e Byttneria fulva $(\bigcirc)$. Figure 2 - Geographical distribution map of Byttneria catalpifolia subsp. catalpifolia $(\star)$ and Byttneria fulva $(\bigcirc)$.
P!, W!) e que foi descrito por Bentham (1851) como uma espécie distinta, Byttneria discolor, tratada como seu sinônimo por Cristóbal (1976). Deste modo, essa é primeira vez que populações de Byttneria fulva são encontradas em 160 anos desde a coleta de Spruce (Fig. 2).

Byttneria fulva pode ser confundida com B. pescapriifolia Britton, por apresentarem o indumento tomentoso das folhas com tricomas estrelados diminutos e adpressos, além do formato das flores e frutos. Entretanto, B. fulva difere de $B$. pescapriifolia por apresentar maior abundância de tricomas ferruginosos nas folhas e ausência de tricomas densamente arranjados sobre as axilas das nervuras secundárias, além de lâminas foliares com base arredondada ou atenuada ( $v s$. cordada ou lobada) (Cristóbal 1976). Segundo BFG (2015), B. fulva ocorre em florestas de várzea, mesmo ambiente em que se registraram os espécimes no Pará.

\section{Agradecimentos}

R.C.S.R. agradece ao Conselho Nacional de Desenvolvimento Científico e Tecnológico (CNPq), a bolsa PIBIC (Processo no 147935/20156) concedida. A.J.F.J e A.K.K. agradecem ao Programa de Capacitação Institucional (MPEG/ MCTI) e ao CNPq, a bolsa de Pesquisa. Assim como a A.L.I.B. agradece ao CNPq, a bolsa de Produtividade em Pesquisa. Agradecemos também ao Sr. Carlos Alvarez, as ilustrações.

\section{Referências}

Bayer C \& Kubitzki K (2003) Malvaceae. In: The families and genera of vascular plants. Vol. 5 . Springer, Berlin. Pp. 225-311.

Bayer C, Fay MF, De Bruijn AY, Savolainen V, Morton CM, Kubitzki K, Alverson WS \& Chase MW (1999) Support for an expanded family concept of Malvaceae within recircumscribed order Malvales: a combined analysis of plastid atpB and rbcL DNA sequences. Botanical Journal of the Linnean Society 129: 267-303.

Bentham G (1851) Second report on Mr. Spruce's collections on dried plants from North Brazil. Hooker's Journal of Botany and Kew Garden Miscellany 3: 165.

BFG - The Brazil Flora Group (2015) Growing knowledge: an overview of seed plant diversity in Brazil. Rodriguésia 66: 1085-1113.

Carneiro-Silva MQ, Koch AK, Viana PL \& Ilkiu-Borges AL (2015) Oncidiinae (Orchidaceae) on the great curve of the Xingu River, Pará state, Brazil. Brazilian Journal of Biology 75: 222-237. 
Cristóbal CL (1976) Estudio Taxonomico del genero Byttneria Loefling (Sterculiaceae). Bonplandia 4: 5-428.

Cristóbal CL (2007) Sterculiaceae of Paraguay. I. Ayenia, Byttneria, Guazuma, Helicteres, Melochia and Sterculia. Bonplandia 16: 5-142.

Cruz FR (2007) Sterculiaceae Vent. no estado de São Paulo. Dissertação de Mestrado. Instituto de Botânica da Secretaria do Meio Ambiente, São Paulo. 120p.

Jacquin NJ von (1797) Plantarum Rariorum Horti Caesarei Schoenbrunnensis 1: 21-22.

Koch AK, Monteiro RF \& Ilkiu-Borges AL (2015) Checklist de Bromeliaceae da região da Volta Grande do Rio Xingu, Pará, Brasil. Rodriguésia 66: 455-464.
NYBG (2016) Virtual Herbarium. Disponível em < http:// sciweb.nybg.org/science2/hcol/lists/sterculiaceae. html>. Acesso em 3 abril 2016.

Pantoja ACC, Ilkiu-Borges AL, Tavares-Martins ACC \& Garcia ET (2015) Bryophytes in fragments of Terra Firme forest on the great curve of the Xingu River, Pará state, Brazil. Brazilian Journal of Biology 75 : 238-249.

Poeppig EF \& Endlicher SFL (1845) Nova Genera et Species Plantarum 3: 73.

Salomão RP, Vieira ICG, Suemitsu C, Rosa NA, Almeida SS, Amaral DD \& Menezes MPM (2007) As florestas de Belo Monte na grande curva do rio Xingu, Amazônia Oriental. Boletim do Museu Paraense Emílio Goeldi, Ciências Naturais 2: 57-153. 